\title{
RAPPORT AND ITS MANAGERIAL IMPLICATIONS IN FM SERVICE OUTSOURCING RELATIONSHIPS
}

\author{
Huiying HOU ${ }^{a, *}$, Daniel Chi Wing HO ${ }^{b}$ \\ ${ }^{a}$ Department of Civil Engineering, The University of Hong Kong, LG207, Composite Building, Pokfulam \\ Road, Hong Kong, China \\ ${ }^{b}$ Department of Real Estate and Construction, The University of Hong Kong, Room 501, Knowles \\ Building, Pokfulam Road, Hong Kong, China
}

Received 12 July 2013; accepted 8 July 2014

\begin{abstract}
In Hong Kong, client companies tend not to renew contracts with relationship partners and may change facilities management (FM) service providers on a frequent basis. This phenomenon is common in the FM industry. Inspired by the phenomenon of changing service providers, this study sheds light on a social relations perspective in outsourcing relationships and aims to investigate the factors that affect FM service outsourcing relationships. Open interviews with 20 FM managers were conducted, and the interview results were analysed with content analysis and coding methods. The empirical findings were interpreted on two levels. First, FM managers believe that rapport is an influential factor that affects FM service outsourcing relationships. Second, the courses in which the interviewees explain the manifestation of rapport and its significance reveal that common goals, shared values, trust, openness, and coordination are the factors that not only nurture the formation of rapport, but also have significant influences on social relations in the process of outsourcing. A framework has been developed to describe the conceptual relationships found in the empirical findings from the interviews. Eight guidelines have been outlined to indicate the managerial implications of this study.
\end{abstract}

KEYWORDS: FM service outsourcing; Outsourcing relationships; Rapport; Social relations; Relational governance

\section{INTRODUCTION}

Facilities management (FM) is a fast-emerging industry and a field that deserves a far greater degree of academic scrutiny than it currently receives (Alexander 2013). In the field of FM service outsourcing, few studies focus on FM service outsourcing relationships as much effort has been committed to issues on maintenance service outsourcing (Lai et al. 2004, 2006, 2008), the FM service market (Bon, Luck 1999; Zhou 2008), contract management (Kadefors 2008), FM characteristics (Chotipanich 2004), sourcing strategies (Alexander 2003; Phil 2001; Hui, Tsang 2004; Salonen 2004) and FM service procurement (Lehtonen, Salonen 2006; Plane, Green 2011).

In the Hong Kong FM industry, client companies tend not to renew contracts with their relationship partners and change FM service provid-

\footnotetext{
* Corresponding author. E-mail: cynthia.hou83@gmail.com
}

ers frequently. This phenomenon is common in the FM industry (IFMA 2006), but has not yet drawn sufficient attention from both FM practitioners and academics. Lehtonen (2006) suggests that collaborative relationships are more efficient than arm's-length relationships in facilities service outsourcing. He conducted a study which identifies the success factors of collaborative relationships in Finland, including mutual trust, commitment, openness, the involvement of different organizational levels, continuous development, the promise of mutual benefits, etc. However, the study was conducted based on literature of inter-organizational relationships in other domains of study. The factors identified by Lehtonen lack theoretical focus without support from well-established theories. Given the lack of studies focusing on human interactions in FM services outsourcing and recognizing that social relations between clients and FM service providers have become a significant feature in outsourcing relationships (Uzzi 1999), 
this study aims to shed light on a social relations perspective of outsourcing relationships and to investigate the factors that affect FM service outsourcing relationships.

This paper is based on 20 open interviews with FM managers at client and facilities management companies in the Hong Kong market. The interviews present two levels of findings. First, rapport and contracts are regarded as two important factors that affect FM service outsourcing relationships. Rapport is believed to play a supplementary role when contracts fail to predict uncertainties that occur among human interactions during the outsourcing process. Rapport affects FM service outsourcing relationships by alleviating the uncertainties that may occur in such relationships. Also, it has positive influences on social relations during the outsourcing process. Third, the courses in which the interviewees explained the manifestation of rapport reveal that common goals, shared values, trust, openness and coordination are the factors that not only nurture the formation of rapport, but also have significant influences on social relations during the outsourcing process. These findings imply that well-managed social relations have significant and positive influences on FM service outsourcing relationships and that relational governance should be applied systematically to manage FM service outsourcing relationships. The findings also reflect that FM managers are relatively unaware of relational governance and lack specific plans to embed the relational factors with a systematic management mechanism. A framework has been developed to describe the conceptual relationships of the empirical findings obtained from the interviews. Eight guidelines have been outlined to indicate the managerial implications of the study.

\section{FM SERVICES AND FM SERVICE OUTSOURCING RELATIONSHIPS}

The definition of FM services has varied with the development of the FM industry (Atkin, Brooks 2000). Traditional FM services are regarded as supporting services, and can include catering, cleaning, waste and recycling management, security, and hospitality. More recently, FM services have grown to include human resources, finance, estate management and business strategy, which are outsourced as parts of a holistic package (Ancarani, Capaldo 2005). At present, FM services emphasize value creation (O'Sullivan et al. 2002; Edvardsson et al. 2005) with the delivery of FM services regarded as a process of creating extra value for clients outside of their core businesses (Lowendahl et al. 2001). The aim of FM service outsourcing has shifted from a focus on cost-saving to an emphasis on adding strategic value to the core business (Hui, Tsang 2004) and achieving efficiency and effectiveness (Dean, Kiu 2001). In this paper, FM service outsourcing refers to a situation in which an organization contracts with another to provide FM services (Barret 1995, 2000).

Traditional FM service outsourcing relationships, which are short-term relationships based on competitive bidding (Mentzer et al. 2000), are arm's length outsourcing relationships that have prevailed in FM for some time. In recent years, a need has arisen to develop outsourcing relationships based on a more collaborative approach (Incognito 2002). Collaborative relationships are ongoing, long-term inter-organizational relationships featuring highly involved strategic management in the outsourcing process aimed at achieving strategic goals (Lehtonen, Salonen 2006). FM service outsourcing relationships in practice fall between arm's length relationships and collaborative relationships (Lehtonen 2006).

Recognizing the strategic significance of outsourcing relationships, clients and consultants intend to build up collaborative relationships at the start of cooperation, but the outsourcing relationships do not create much strategic value for top management during the outsourcing process (Lehtonen, Salonen 2006). One significant reflection is the frequent turnover in service providers in the FM outsourcing sector. Therefore, seeking strategic value in outsourcing relationships has become an important objective of FM managers in recent years (Alexander 2003). In today's organizations, strategic value is derived from enhancing work efficiency. FM service delivery is heavily reliant on human labour and the numerous human interactions that occur on a daily basis. Well-managed social relations have proved to enhance work efficiency in the outsourcing process (Lee, Kim 1999; Goles, Chin 2005). In other words, well-managed social relations create strategic value to outsourcing relationships by enhancing working efficiency. Therefore, social relations in the area of FM service outsourcing are now an important issue, and deserve comprehensive investigation (Poppo, Zenger 2002).

\section{RAPPORT IN THE CONTEXT OF INDIVIDUAL INTERACTIONS}

Rapport has not been the focus of any studies on FM and has rarely been investigated in inter-firm 
relationships. However, it has been studied in the context of individual interactions (Gremler, Gwinner 2000). Although there is no clear definition of rapport, its nature has already been studied thoroughly. Theories on rapport involve three behavioural components: mutual attention, positivity and coordination (Nadler 2003).

According to Nadler (2003), mutual attention reflects a scenario in which both participants want to interact with each other and feel involved in the interaction. Positivity describes both participants' attitudes towards the interaction and its results. Gremler and Gwinner (2000) interpret positivity in rapport as an enjoyable interaction, which includes a feeling of caring and friendliness. Rapport-related coordination is the most complex component. Coordination in rapport refers to a situation in which participants in an interaction seek a balanced or harmonious outcome by giving positive responses such as reacting immediately, spontaneously, and sympathetically to the sentiments and attitudes of each other (Tickle-Degnen, Rosenthal 1990). Figure 1 was developed to illustrate the behavioural components and their relationships to rapport.

Rapport is derived from social relations and is considered to be a state that relationship partners aim to achieve. The advantage that rapport brings to an outsourcing relationship is that it can eliminate possible uncertainties in the outsourcing process, especially those that occur in human interactions. With a certain degree of rapport, relationship partners can make appropriate decisions by predicting their partners' reactions towards the issues when vocal responses are absent. The accuracy of predictions is determined by their frequency and quality. In other words, rapport forms

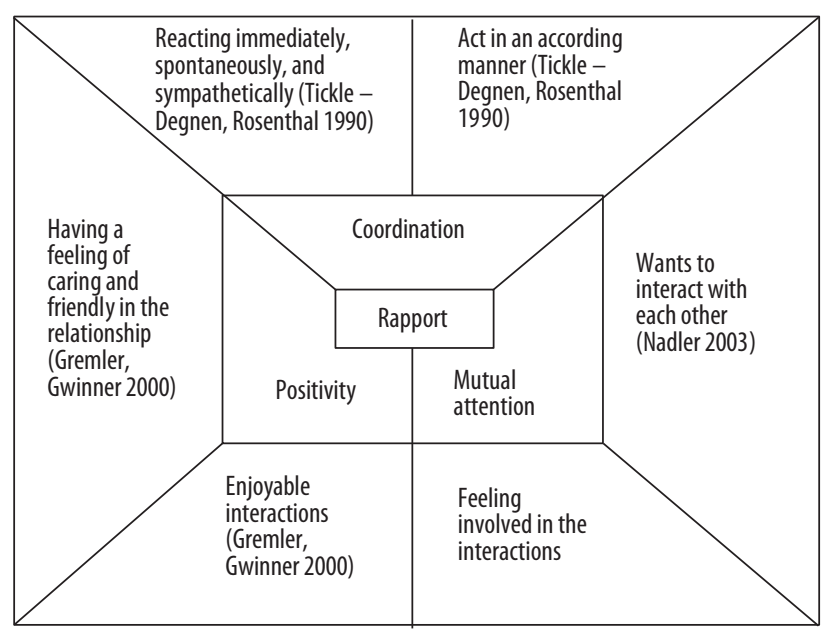

Fig. 1. Rapport and its behavioural components through multiple positive interactions among relationship partners. In this study, it refers to positive feelings that are spontaneously formed in the course of multiple positive interactions. It influences relationship partners' attitudes towards each other through their interactions and governs their behaviour.

\section{SOCIAL RELATIONS AND RELATIONAL GOVERNANCE}

The concept of social relations has been gaining attention as inter-firm exchanges are repeated exchanges embedded in social relations (Poppo, Zenger 2002), which affect the quality of inter-firm relationships (Uzzi 1999). Therefore, the governance of social relations becomes necessary as they emerge from the values and agreed-upon processes found in such relations (Poppo, Zenger 2002). Such governance is regarded as relational governance.

Williamson and Winter (1993) indicates the incompleteness of contracts in governing inter-firm relationships in that the contracting parties (human) are subject to bounded rationality and given to opportunism. Relational governance is viewed as a governing mechanism that is supplementary to contractual governance ( $\mathrm{Yu}$ et al. 2006). It is defined as "an endogenous mechanism that aims to enhance exchange performance by embedding private and public information flows in a matrix of social ties rather than by resorting to a contract or its enforcement by a third party" (Ferguson et al. 2005: 221). In other words, this statement means that in a business-to-business relationship with multiple interactions between the parties, sound social relations can help enhance the performance of the relationships. Sound social relations are established during interactions with purposive relationship embeddedness from the partners, such as trust, openness, etc. Relational governance is a management mechanism of managing the relationship embeddedness to influence social relations. In contrast to formal contracts, relational governing stresses more on interactions between parties (Gundlach, Achrol 1993) and emphasizes "informal self-enforcing governance" (Dyer, Singh 1998).

In this study, relational governance is regarded as a procedure that involves the establishment, reinforcement and regulation of social components to enhance performance ( $\mathrm{Yu}$ et al. 2006). Social components are also known as social norms, which are "rules" that govern people's values, beliefs, attitudes, and behaviors, but that which not promulgated by an official source nor enforced by legal 
sanctions (Posner 1997). In inter-firm relationship studies, scholars tend to explore social norms to understand the nature of relationships and investigate efficient management mechanism. There is a lack of studies of outsourcing relationships from a social relation perspective in the area of FM, so it is necessary to investigate the social components in outsourcing relationships in order to develop an efficient management mechanism.

\section{METHODOLOGY}

This study was initiated by an observation of a common phenomenon in Hong Kong: the clients tend to change FM service providers frequently. With this initiation, this study was designed to explore the issues that affect FM service outsourcing relationships." Such an explorative inquiry requires data that provides rich information on the FM service outsourcing process and the interactions between clients and service providers. According to the nature of explorative inquiry, a qualitative paradigm has been adopted for this study.

This study explores in depth the issues that affect FM service outsourcing relationships. Therefore, interviews were adopted as the main research tool for data collection. Over a six month period beginning in November 2012, 20 interviews were conducted in a semi-structured manner with the support of an interview guide. During each inter- view, the guide provided a basic framework for the interviewer, who asked questions found in the guide while also using a probing technique to gain more detailed information (Wimmer, Dominick 1987). Each interview lasted approximately one hour. The sampling of the interviewees is based on non-probability sampling. This sampling method is regarded as "the most effective method for studying a certain domain with knowledgeable experts within" (Tongco 2007). Due to the specific focus of this study on FM service outsourcing relationships, 20 experienced FM managers were selected from large companies.

Given that the truth of findings rests largely on the experience-based personal opinions of the FM managers, this study targets FM director or senior FM managers who have more than 10 years working experience in the FM industry. In order to obtain balanced views from both sides of the outsourcing relationships, the interviewees selected include representatives from both the client and service provider side. Also, this study selected client side interviewees from a variety of businesses with the aim of increasing the validity of the sample. In summary, 10 of the interviewees worked at client side organizations, including two banks, three educational institutions, three government bodies, one science park and one hospital. The other 10 interviewees represented different FM service providers. Table 1 lists the backgrounds of the interview participants.

Table 1. Background of the participants

\begin{tabular}{lll}
\hline Job Title & Affiliation & Number \\
\hline Director (facilities and campus management) & Client & 1 \\
Director & Client & 4 \\
Senior facilities manager & Client & 4 \\
Senior manager in facilities management & Client & 1 \\
FM director & Service provider & 4 \\
Senior facilities manager & Service provider & 6 \\
\hline
\end{tabular}

Table 2. Interview guide for the study

\begin{tabular}{ll}
\hline Categories & Questions \\
\hline Basic information & $\begin{array}{l}\text { 1. First of all, I would like to know something about you. Could you please } \\
\text { briefly introduce yourself, say, your educational background, your career } \\
\text { background, your position in this organization and your daily duties at this } \\
\text { position? } \\
\text { 2. What FM services are outsourced by your organization? / What FM services } \\
\text { does your company provide? }\end{array}$ \\
& $\begin{array}{l}\text { 3. What do you think affects FM service outsourcing relationships? } \\
\text { 4. Can you share with me some examples to demonstrate the issues that you } \\
\text { mentioned? }\end{array}$ \\
$\begin{array}{l}\text { services outsourcing relation- } \\
\text { ships }\end{array}$ & Why is it important? \\
\hline
\end{tabular}


Table 3. Codes created for analyses

\begin{tabular}{lll}
\hline Group 1: Interview guide topics & Group 2: Key quotes & Group 3: Summary and interpretation \\
\hline Basic information: Q1 & Rapport: Q3.1 & Adaptation: Q4.1 \\
FM service outsourced (provid- & Mutual understanding: Q3.2 & Conflicts: Q4.2 \\
ed) by the organization: Q2 & Cooperative spirit: Q3.3 & Common goals: Q5.1 \\
Issues that affect FM service & Amicable collaboration experience: & Shared value: Q5.2 \\
outsourcing relationships: Q3 & Q3.4 & Trust: Q5.3 \\
Examples: Q4 & Organization policies: Q3.5 & Openness: Q5.4 \\
Elaboration: Q5 & Contract/contractual clauses/contrac- & Coordination: Q5.5 \\
& tual governance: Q3.6 & \\
& Human: Q3.7 & \\
& Inner connection: Q.3.8 & \\
& FM performance/performance: Q3.9 & \\
& Service level agreements: Q3.10 & \\
& Coordination: Q3.11 & \\
& Competition: Q3.12 & \\
& Market: Q.13 & \\
& Commitment: Q3.14 & \\
& Sound interaction: Q3.15 & \\
&
\end{tabular}

The interview guide for the study, shown below in Table 2, contains two parts: basic information and personal opinions. Question 1 was designed to obtain background information on the interviewees and create a casual atmosphere between the interviewer and the interviewee. Question 2 was designed to obtain FM service outsourcing information on the organization that the interviewees represented; Question 3 was asked to gauge the interviewees' personal opinions on the issues that affect FM service outsourcing relationships. Questions 4 and 5 were designed to probe for more information relating to question 3 .

The responses from the interviewees were recorded with their permission and transcribed into notes for data analysis. Content analysis and coding methods as described by Corbin and Strauss (2008) were employed to analyze the data in a three-step process. The first step of the analysis was descriptive in nature, with direct answers being collated and described. The second step was summative, identifying the themes in the data and grouping them into relevant categories. In this step, important terms or relevant phrases that were strongly emphasized by or frequently referred to by the interviewees were highlighted in the notes and categorized. The first and second steps are processes of descriptive coding. The third step was interpretive, seeking the relationships among the categories and integrating the data into one explanatory framework. This analytic process is an example of interpretive coding, which requires intensive interpretation of data that has been categorized in the previous steps to extract the relationships between the different categories.

Three groups of codes were created in the analytic process. The first group of codes was created to obtain an overall structure of the contents of each interview, which were divided into five parts marked by codes that were created based on the questions from the interview guide. They were coded Q1 to Q5. The second group of codes were created to highlight the issues or concepts that were regarded as important. Some expressions showed intense similarity and were marked with the same codes in the coding process, e.g. contract, contractual clauses, and contractual governance. They were coded Q3.1 to Q3.15. Q4.1 and Q4.2 were created by comparing the examples that the interviewees shared in answering Question 4. The examples were mainly about uncertainties that occur in the outsourcing process and how the previously mentioned issues were manifested. They describe the types of uncertainties that occur in the outsourcing process. Q5.1 - Q5.5 were created based on an interpretation of the responses to Question 5 . In the course of explaining the issues that affect FM service outsourcing relationships and their significances, the interviewees highlighted some factors and their relationship to rapport. The factors were recognized from the answers, and were coded Q5.1 to Q5.5.

\section{THE ROLE OF RAPPORT IN FM SERVICE OUTSOURCING RELATIONSHIPS}

In response to the question "What do you think affects FM service outsourcing relationships?”, rapport and contracts are regarded as two important factors that affect FM service outsourcing relationships.

As shown in Figure 2, contracts with their related expressions, e.g. contractual clauses, contractual governance, and service level agreements, 
Rapport, mutual understanding, cooperative spirit, amicable collaboration experience, organization policies, rapport, contracts, Human, inner connection, FM performance, rapport, Performance, contracts, service level agreements, rapport, CONTRACTUAL CLAUSES, coordination, Competition, market, commitment, rapport contractual governance, sound interaction

Fig. 2. Key words coded from the answers to Question 3

appeared five times, while rapport also appeared five times. This means that five interviewees regard contracts to be an influential factor in FM service outsourcing relationships while another five believe that rapport affects FM service outsourcing relationships.

When citing contracts, the interviewees specifically referred to their governing power. The interviewees from the client side emphasized the constraining power and punitive systems of outsourcing contracts. They believe that contracts can constrain human behaviour by clearly specifying potential penalties. In FM outsourcing contracts, service level agreements (SLAs) are specified. The SLAs specifically indicate the delivery time and payments, key performance indicators (KPIs), submission of performance reports, incentives and penalties, customer satisfaction scoring and feedback to the service provider for further action. With the SLAs, the client can monitor the performance of service suppliers and guarantee its own interests when service providers fail to perform up to the standards specified in the SLAs. The interviewees from the service provider side viewed SLAs as important guidelines, stating that they fully respect the spirit of contracts and commit considerable effort to fulfilling their obligations as set forth in the contracts. By doing so, that they build their reputations and demonstrate professionalism in the industry.

Rapport was cited as another important factor that affects FM service outsourcing relationships. According to the interviewees, rapport is an indispensable element of sound social relations. It helps nurture sound social relations and is more efficient than contracts in dealing with uncertainties in the outsourcing process. Some interviewees contended that although contracts attempt to cover as many aspects as possible, uncertainties can still lead to situations that are beyond the scope of a contract. They added that contractual clauses cannot reach the core of human interactions, but rapport can manage social relations so as to mitigate contradictions or conflicts, and facilitate further cooperation between relationship partners. For example, one FM manager stated that a relationship partner usually develops a sense of antagonism when he talks to them about contract. He regards the contract to be too rigid to manage a social relationship as he believes that rapport is more efficient in "getting things done". A second FM manager who works on the service provider side experienced an intense argument initiated by a client due to a disagreement over a contractual clause. He recalled that the ambiguous contractual clause did not affect the work performed, but the argument over it damaged the relationship. He learned a lesson from the incident and related the incident to the absence of rapport. A third FM manager considers rapport to be the most influential factor to affect FM service outsourcing relationships because it is an "unspoken agreement between the relationship partners" and reduces the amount of time for back-and-forth communications. For the other interviewees who highlighted rapport, they shared their experiences in managing outsourcing relationships, which instead emphasize the outsourcing contracts to their relationship partners. They engage their relationship partners by "having small chats," "having a drink after work," "organizing charity activities," "going the extra mile for convenience's sake," etc., to enhance their mutual understanding with their partners and, most importantly, to nurture rapport. These examples reveal the influence of rapport on FM service outsourcing relationships.

Aside from contract and rapport, the rest of the keywords only appear once in Figure 1, meaning that they were mentioned by only one interviewee. Compared to contract and rapport, they are regarded as less significant in influencing FM service outsourcing relationships, but they indicate the significance of social relations in FM service outsourcing because most are reflections of social relations, e.g. mutual trust, cooperative spirit, amicable collaboration experience, inner connection, coordination, commitment, sound interaction, etc. They reflect the different behavioural components of rapport. Based on the frequency of the codes of rapport and its behavioural components, rapport was mentioned the most by the interviewees from different companies. It can be concluded that rapport plays a significant role in affecting FM service outsourcing relationships and that its significance lies in the fact that it outweighs contracts in managing some uncertainties in the outsourcing process. 


\section{MANIFESTATION OF RAPPORT IN FM SERVICE OUTSOURCING RELATIONSHIPS}

The interviewees were asked to raise examples to demonstrate their opinions on the issues that affect FM service outsourcing relationships. Their examples mainly involve uncertainties that occur during the FM service outsourcing process. The interviewees used them to reveal the reactions of the two sides of the relationship to the uncertainties. The uncertainties they described were divided into two categories: adaptation between the relationship partners and conflicts between service providers and users.

Adaptation refers to situations in which relationship partners encounter contradictions, with one side, instead of fighting for short-term interests, chooses to adapt to the other side's agenda in order to maintain harmony. Adaptation occurs on a frequent basis in FM service outsourcing. Service providers usually compromise their own interests and fulfill the extra requirements requested by their clients such as switching materials, overtime work on weekends, providing more manpower or services, etc. Clients also accommodate service providers with extra allowances for their staff, extending of staff contracts, increasing welfare provisions, etc. These examples reveal that the relationship partners show spontaneous and sympathetic reaction to each other, which is one of the important dimensions of rapport. Some interviewees give credit to rapport for enabling them to show a positive posture based on a mutual understanding of each other. Clients generally regard rapport as altruism, while consultants view its manifestation of rapport as willingness to compromise. Both sides suggested that rapport is a product of "emotional investment". Mutual favours for each other and achieving compromise are both "emotional investments" that are employed with the aim of receiving similar treatment in return when needed.

Conflicts usually occur in the form of complaints from the service users and involve three parties: the service users, the client and the service provider. In a conflict, service users usually complain to the consultants about the quality of the services provided. Clients are involved when service providers do not succeed in mitigating the conflicts or even escalate the conflicts. In some situations, they must take charge of the situation to balance the service users and the service provider. Service users expect the clients to provide a fair judgment on the situation and to arrange appropriate compensation for them. In some cases, service users use extreme means to corner the clients and service providers into embarrassing situations, e.g. tenants blocking the entrance of parking lots to show their dissatisfaction towards parking fees, tenants threatening to call the police to escalate the issue, etc. Under such circumstances in which relationship partners do not have any opportunity to communicate with each other at the first place, they made appropriate decisions by predicting each other's reaction on the uncertainties. The accuracy of the prediction depends on the existence of rapport between the relationship partners. Rapport manifests in these examples as the understanding of each other's principles, values and habits. They help the relationship partners to act accordingly when uncertainties occur.

According to the interviewees, under both types of uncertainty, rapport between the client and service provider is very important. When uncertainties occur, there is limited time for FM practitioners to resort to contracts or for discussion between the clients and service providers. Also, contract clauses cannot predict the uncertainties, nor do they provide relevant solutions to them. The relationship partners are put in a situation in which they can only rely on their management skills or previous work experiences. For the interviewees who reported that rapport is an influential factor that affects FM service outsourcing relationships, they believe that rapport helps the relationship partners deal with uncertainties better. As demonstrated in the examples, rapport manifests itself as altruism and the reciprocity of positivity between clients and consultants. It motivates relationship partners to support and coordinate its activities with the other party during the outsourcing process, and has been demonstrated to play an influential role in managing social relations in FM service outsourcing relationships. Implicitly, rapport affects FM service outsourcing relationships by undermining uncertainties and facilitating collaboration. A sound relationship nurtured with rapport can save clients extra efforts in monitoring service providers. Rapport represents an intangible asset which is of great strategic value to FM service outsourcing relationships. Recognizing this, FM managers believe that it is necessary to develop rapport even though it takes a considerable amount of time.

\section{RAPPORT AND ITS ANTECEDENTS IN FM SERVICE OUTSOURCING RELATIONSHIPS}

Rapport is not formed spontaneously nor does it exist at the beginning of a relationship. It is built 
upon gradual accumulation of interactions during the outsourcing process. Its origins and development are difficult to identify. Therefore, it is difficult to address its formation. However, in the course of explaining the opinions on rapport, the interviewees highlighted a number of factors and elaborated on the close relationship between those factors and rapport, namely common goals, shared values, trust, openness and coordination.

The conclusion that the five factors are antecedents of rapport is deduced from a series of statements from the interviewees' responses. The statements were coded and divided into two categories as shown in Figure 3. The first category indicates that the factors have close relationships with rapport, and are indispensable to it. Four examples are shown in Rectangular 3 in Figure 3. The second category is less straightforward in relating the factors to rapport. However, further interpretation of the statements revealed that the factors have significant influences on certain behaviour, such as "working in the same direction", "guiding the behaviour of the relationship partners", "acting accordingly", "getting along with each other better", etc. The behaviour reflects the behavioural components of rapport. It implies that the existence of the factors is important to rapport and they facili- tate its formation. Eight examples are illustrated in Figure 3.

Common goals lead relationship partners to work in the same direction and set important milestones for relationship partners in long-term cooperative relationships. Sound FM performance is usually the most important common goal that relationship partners aim to achieve in FM service outsourcing. Good common goals imply more than achievements - they also synthesize resources and build team spirit. Shared values are fundamental beliefs that guide the behaviour of the relationship partners. They can be interpreted in various ways in different outsourcing relationships. For example, price-driven outsourcing and performance-driven outsourcing display two different values adopted in outsourcing. The latter has been a recent trend in FM service outsourcing, while the former is seldom practiced in the FM industry. Nowadays FM managers place more value on the performance of FM. They also value integrity, explicitness, customer priority service, long-term cooperation, etc. Whether or not relationship partners can provide an equal amount of emphasis on the same values determines the degree of mutual understanding and behavioural consensus, which are the foundations of rapport.

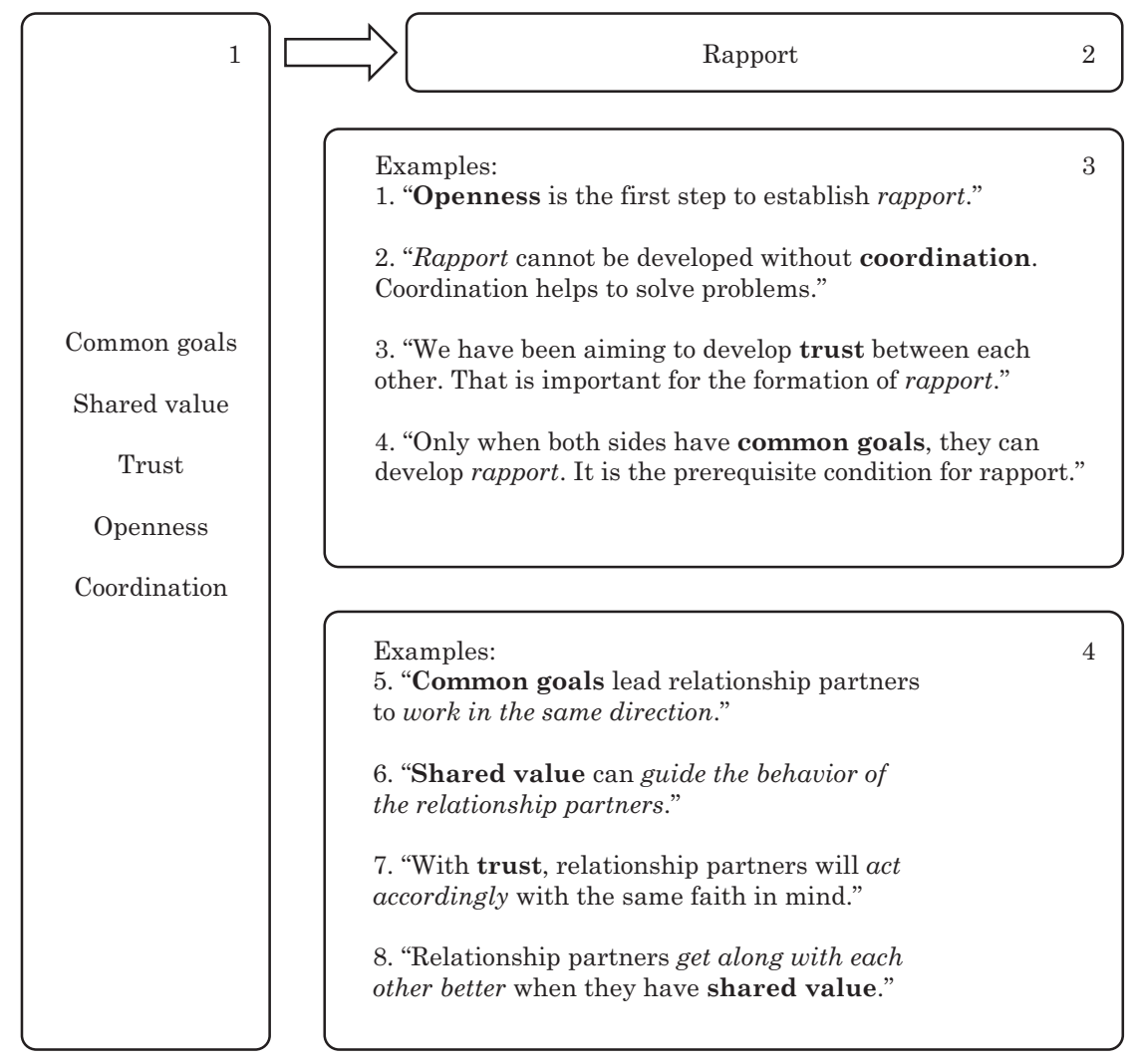

Fig. 3. Demonstration of data analyses 
Trust is an important foundation of rapport. In FM service outsourcing relationships, trust is faith in reciprocal behaviour with the goal of positivity in the long run. Trust helps to build up rapport in terms of mutual understanding, support, and encouragement. The FM managers interviewed revealed that when necessary, they choose to forgive, tolerate, or sacrifice in order to mitigate contradictions, and such behaviour is considered worthwhile for future favours in return. With mutual trust, relationship partners prioritize common interests and will act within each other's expectations accordingly. It takes time and effort to build up trust in a relationship. The observations, interactions and understanding accumulated build a sense of trust during the outsourcing process. Once trust is established, it can elevate the degree of rapport in a significant way thus affecting FM service outsourcing relationships.

Openness involves the sharing of both operational information and ideas. The former is a prerequisite condition for FM service outsourcing relationships. As such, contracts are designed to explicitly illustrate the frequency and forms of interactions in order to secure the sharing of operational information, e.g. through regular meetings, regular reports, etc. Openness also leads to a friendlier atmosphere in which FM practitioners are more willing to provide comments and to share suggestions. Openness cannot be governed by contracts, which can guarantee a certain number of interactions between clients and consultants, but cannot force or bring about an exchange of ideas and suggestions. FM managers believe that openness ensures that relationship partners make decisions and act appropriately with regard to each other's interests. Rapport is a sense of inner-connection between relationship partners that is built through multiple interactions with sound information sharing, especially of strategic information such as long-term objectives, business plans, marketing strategies, etc. Openness can elevate the degree of rapport to a strategic level in an outsourcing relationship. In other words, openness affects FM service outsourcing relationships.

Coordination is a process of balancing the differences between relationship partners and arranging better solutions for each other in outsourcing. It is an important component of rapport. The FM managers reveal that coordination is highly advocated between relationship partners, and is believed to be indispensable in a sound outsourcing relationship. Coordination manifests itself at both the operational and the managerial levels.
At the operational level, FM practitioners expend much effort to adjust their own interests towards a larger goal and to handle issues in a harmonious manner. At the managerial level, FM managers coordinate with each other with the aim of reinforcing positivity in outsourcing relationships because they believe that positivity is the fundamental basis for daily interactions. A higher degree of coordination leads to a greater possibility of developing rapport, which increases the smoothness of FM service delivery and improves the performance of FM. Coordination has a direct influence on FM service outsourcing relationships.

\section{MANAGERIAL IMPLICATIONS AND MANAGERIAL GUIDELINES}

A framework of FM service outsourcing relationships has been developed based on the interpretation of findings from the interviews. It is shown in Figure 4.

During the study, the interviewees emphasized contract and rapport equally. They believe that both contract and rapport are able to manage FM service outsourcing relationships. Using a contract to manage an FM service outsourcing relationship is regarded as contractual governance. Aside from contractual governance, the interviewees suggested that rapport can also manage FM service outsourcing relationships. The emphasis on rapport and its behavioural components reveals that social relations in FM service outsourcing relationships have become a concern for FM managers. Uncertainties that arise from social relations are less likely to be managed by contracts or other organizational rules. The negative influences caused by uncertainties may harm FM service performance and thus affect FM service outsourcing relationships. Rapport facilitates the cohesiveness of social relations by alleviating the uncertainties that occur in human interactions. Rapport feeds off each partner's positive feelings for each other. Such feelings accumulate naturally during their daily interactions and enable the partners to coordinate with each other when uncertainties occur. Also, rapport manages social relations by assuring FM practitioners that their relationship partners display agreed-upon behaviours to achieve efficiency. However, rapport is not an abstract concept and its existence is neither visible nor measurable. It is impossible to mark the establishment or to measure the degree of rapport, which forms naturally while hardly being realized by FM practitioners. The FM managers interviewed spoke highly of 


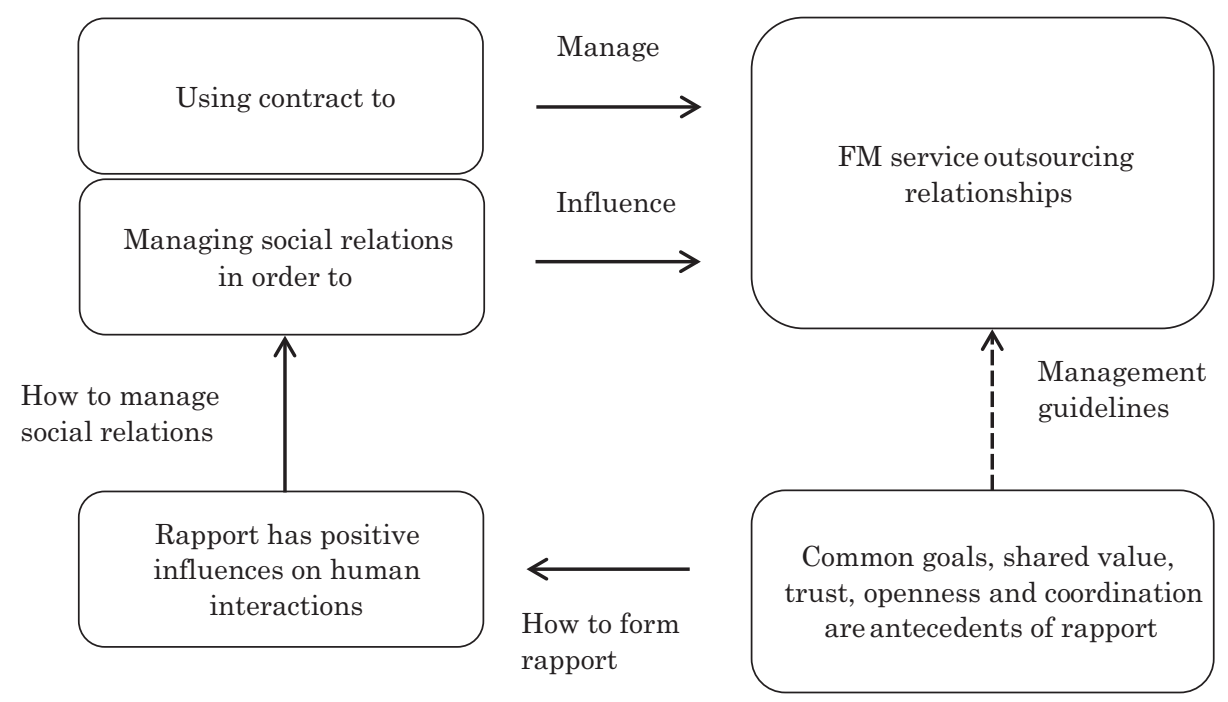

Fig. 4. A framework of the empirical findings

rapport, but could not come up with a management mechanism for developing rapport. They highlighted common goals, shared values, trust, and coordination, and suggested that they are the antecedents of rapport.

Common goals, shared values, trust, openness and coordination are all social components that are related to social relations. They are believed to affect social relations by governing people's behaviours. The governing processes are not enforced by any legal sanctions. These social components are social norms agreed upon by both sides of the relationships and are spontaneously set as basic behavioural principles. From a relationship management perspective, the process of developing agreed-upon social norms that govern human behaviour in inter-firm relationships is regarded as relational governance. The empirical findings imply that relational governance is applied in FM service outsourcing relationship management, but an awareness of it is relatively low in practice. The five factors are not systematically embedded into the management mechanism. FM managers recognize the importance of relational governance and try to manage outsourcing relationships by developing the five factors of common goals, shared values, trust, openness and coordination. However, they do not have any specific plans to reinforce these factors in a systematic way. Recognizing this management gap in FM service outsourcing relationships, eight managerial guidelines have been outlined for FM practitioners to understand the five factors and to implement specific plans to reinforce them during the outsourcing process.
Table 4. Managerial guidelines for relational governance in FM service outsourcing

1 Establish common goals at the beginning of an outsourcing relationship and embed them into the relationship.

2 Establish shared values with relationship partners and reinforce them during the outsourcing process.

3 Nurture mutual trust during the personal interactions by initiating communication, offering help, showing a willingness to adapt to the partners, etc.

4 Provide opportunities for relationship partners to share information, ideas, comments, suggestions, etc.

5 Create an open atmosphere and encourage FM practitioners to communicate in an open-minded manner.

6 Achieve a better understanding of the relationship partners' goals, values, needs, work habits, organizational culture, etc. for further coordination.

$7 \quad$ Enhance coordination among relationship partners in support of operational functions in order to achieve strategic goals.

8 Maintain positive interactions with relationship partners and a relaxed relationship with them.

\section{CONCLUSIONS}

This study has explored important factors that affect FM service outsourcing relationships. The FM managers interviewed in this study suggested that rapport is a significant factor that affects FM service outsourcing relationships, implying that social relations play an important role in managing FM service outsourcing relationships. The empirical findings reflect that rapport is a mediating factor. Common goals, shared values, trust, openness and 
coordination are antecedents that affect outsourcing relationships. They help in the formation of rapport and exert positive influences on FM service outsourcing relationships. The findings also reveal that FM managers currently exert more emphasis on social relations in the FM service outsourcing process. FM managers can benefit from the findings by adopting the eight managerial guidelines developed in this study. These managerial guidelines have enhanced the FM managers' awareness of the management of social relations and provide useful instructions for practice.

This study needs further elaboration with a larger sample size in order to generalize the findings. In a larger sample study, the frequency of rapport in the interviews may change, but the findings of this study reveal that rapport can very well make a significant appearance in a larger sample study. Furthermore, while study only focuses on human interactions in FM service outsourcing relationships, FM service outsourcing is an integrated process that affected by a great number of factors such as economic factors, organizational factors, etc. In the near future, it is believed that as the FM industry continues to mature, social relations will play a more important role in creating strategic value to the FM service outsourcing. Future investigation should adopt an integrated approach to study FM service outsourcing relationships in order to depict a more holistic picture of FM service outsourcing relationships.

\section{REFERENCES}

Alexander, K. 2003. A strategy for facilities management, Facilities 21(11/12): 269-274. http://dx.doi. org/10.1108/02632770310500338

Alexander, K. 2013. Facilities management: theory and practice. Routledge.

Ancarani, A.; Capaldo, G. 2005. Supporting decisionmaking process in facilities management services procurement: a methodological approach, Journal of Purchasing and Supply Management 11(5-6): 232-241. http://dx.doi.org/10.1016/j.pursup.2005.12.004

Atkin, B.; Brooks, A. 2000. Total facilities management. Oxford: Blackwell Science.

Barret, P. 1995. Facilities management: towards better practice. Oxford: Blackwell Science.

Barret, P. 2000. Achieving strategic facilities management through strong relationships, $F a$ cilities 18(10-12): 421-426. http://dx.doi. org/10.1108/02632770010349655

Bon, R.; Luck, R. 1999. Outsourcing of property-related management functions in Europe and North America, 1993-1998, Construction Manage- ment and Economics 17: 409-412. http://dx.doi. org/10.1080/014461999371321

Chotipanich, S. 2004. Positioning facility management, Facilities 22: 364-372. http://dx.doi. org/10.1108/02632770410563086

Corbin, J.; Strauss, A. 2008. Basics of qualitative research: techniques and procedures for developing grounded theory. Sage Publications, Inc.

Dean, A. M.; Kiu, C. 2001. Performance monitoring and quality outcomes in contracted services, International Journal of Quality \& Reliability Management 19(4): 396-413. http://dx.doi. org/10.1108/02656710210421571

Dyer, J. H.; Singh, H. 1998. The relational view: cooperative strategy and sources of inter-organizational competitive advantage, Academy of Management Review 23(4): 660-679.

Edvardsson, B.; Gustafsson, A.; Roos, I. 2005. Service portraits in service research: a critical review, International Journal of Service Industry Management 16(1): 107-121. http://dx.doi. org/10.1108/09564230510587177

Ferguson, R. J.; Paulin, M.; Bergeron, J. 2005. Contractual governance, relational governance, and the performance of interfirm service exchanges: the influence of boundary spanner closeness, Journal of the Academic of Marketing Science 33(2): 217-234. http://dx.doi.org/10.1177/0092070304270729

Goles, T.; Chin, W. W. 2005. Information systems outsourcing relationship factors: detailed conceptualization and initial evidence, $A C M S I G$ MIS Database 36(4): 47-67. http://dx.doi. org/10.1145/1104004.1104009

Gremler, D. D.; Gwinner, K. P. 2000. Customer-employee rapport in service relationships, Journal of Service Research 3(1): 82-104. http://dx.doi. org/10.1177/109467050031006

Gundlach, G. T.; Achrol, R. S. 1993. Governance in exchange: contract law and its alternatives, Journal of Public Policy \& Marketing 12(2): 141-155.

Hui, Y. Y.; Tsang, H. C. 2004. Sourcing strategies of facilities management, Journal of Quality in Maintenance Engineering 10(2): 85-92. http://dx.doi. org/10.1108/13552510410539169

IFMA. 2006. An inside look at FM outsourcing [online] International Facility Management Association. Available at: http://www.ifma.org/publications/ books-reports/an-inside-look-at-fm-outsourcing [accessed 6 September 2014]

Incognito, J. D. 2002. Outsourcing: ensuring survival with strategic global partners, Journal of Facilities Management 1(1): 7-15. http://dx.doi. org/10.1108/14725960310807809

Kadefors, A. 2008. Contracting in FM: collaboration, coordination and control, Journal of Facilities Management 6: 178-188. http://dx.doi. org/10.1108/14725960810885943

Lai, J. H. K.; Yik, F. W. H.; Jones, P. 2004. Practices and performance of outsourced operation and maintenance in commercial buildings, in Proceedings of the CIBW70 2004 Hong Kong International Symposium: Facilities Management and Maintenance, 7-8 December 2004, Hong Kong SAR, 357-367. 
Lai, J. H. K.; Yik, F. W. H.; Jones, P. 2006. Critical contractual issues of outsourced operation and maintenance service for commercial buildings, International Journal of Service Industry Management 17(4): 320-343. http://dx.doi. org/10.1108/09564230610680640

Lai, J. H. K.; Yik, F. W. H.; Jones. P. 2008. Expenditure on operation and maintenance services and rental income of commercial buildings, Facilities 26(5/6): 242-265. http://dx.doi. org/10.1108/02632770810865014

Lee, J.; Kim, Y. 1999. Effect of partnership quality on IS outsourcing success: conceptual framework and empirical validation, Journal of Management Information System 15(4): 29-61. http://dx.doi. org/10.2307/249407

Lehtonen, T. 2006. Collaborative relationships in facility services, Leadership \& Organization Development Journal 27: 429-444. http://dx.doi. org/10.1108/01437730610687746

Lehtonen, T.; Salonen, A. 2006. An empirical investigation of procurement trends and partnership management in FM service - a Finnish survey, International Journal of Strategic Property Management 10(2): 65-78. http://dx.doi.org/10.1080/164 8715X.2006.9637545

Lowendahl, B. R.; Revang, O.; Fosstenlokken, S. M. 2001. Knowledge and value creation in professional service firms: a framework for analysis, Human Relations 54(7): 911-931. http://dx.doi. org/10.1177/0018726701547006

Mentzer, J.; Min, S.; Zacharia, Z. 2000. The nature of inter-firm partnering in supply chain management, Journal of Retailing 76(4): 549-568. http://dx.doi. org/10.1016/S0022-4359(00)00040-3

Nadler, J. 2003. Rapport in negotiation and conflict resolution, Marquette Law Review 87(4): 875-881.

O'Sullivan, J.; Edmond, D.; Hosfstede, A. 2002. What's in a service? Towards accurate description of nonfunctional service properties, Distributed and Parallel Databases Journal 12(2/3): 117-133. http:// dx.doi.org/10.1023/A:1016547000822

Phil, R. 2001. Corporate competence in FM: current problems and issues, Facilities 19(7/8): 260-275.
Plane, C. V.; Green, A. N. 2011. Buyer-supplier collaboration: the aim of FM procurement?, Facilities 30(3/4): 152-163. http://dx.doi.org/10.1108/ 02632771211202851

Poppo, L.; Zenger, T. 2002. Do formal contracts and relational governance function as substitute or complements?, Strategic Management Journal 23(8): 707-725. http://dx.doi.org/10.1002/smj.249

Posner, R. A. 1997. Social norms and the law: an economic approach, American Economic Review 87(2): 365-369.

Salonen, A. 2004. Characteristics of facility service industry and effects on buyer-supplier relationships, Nordic Journal of Surveying and Real Estate Research 2: 31-46.

Tickle-Degnen, L.; Rosenthal, R. 1990. The nature of rapport and its nonverbal correlates, Psychological Inquiry: An International Journal for the Advancement of Psychological Theory 1(4): 285-293. http:// dx.doi.org/10.1207/s15327965pli0104_1

Tongco, M. D. C. 2007. Purposive sampling as a tool for informant selection, Ethnobotany Research \& Applications 5: 147-158.

Uzzi, B. 1999. Embeddedness in the making of financial capital: how social relations and networks benefits firms seeking financing, American Sociological Review 64(4): 481-505. http://dx.doi. org/10.2307/2657252

Williamson, O. E.; Winter, S. G. 1993. The nature of the firm: origins, evolution and development. Oxford University Press.

Wimmer, R. D.; Dominick, J. R. 1987. Mass media research: an introduction. Belmont, MA: Wadsworth.

Yu, C. M. J.; Liao, T. J.; Lin, Z. D. 2006. Formal governance mechanisms, relational mechanisms and transaction-specific investment in supplier-manufacturer relationships, Industrial Marketing Management 35(2): 128-139. http://dx.doi.org/10.1016/j. indmarman.2005.01.004

Zhou, M. Q. 2008. FM market research review: do we really have the "intelligence"?, Facilities 26(11/12): 45462. http://dx.doi.org/10.1108/02632770810895714 